Egyptian

Orthodontic Journal

\title{
ACCURACY OF CONE BEAM-DERIVED LATERAL CEPHALOMETRIC RADIOGRAPHS
}

\author{
Saba Al-Hadithiy ${ }^{1}$, BDS, MSc, MOrth (RCSEd), \\ Khaled Hazem Attia ${ }^{2}$, BDS, MSc, PhD, \\ Amr Emad El-Dakroury ${ }^{3}$, BDS, MSc, PhD
}

\section{ABSTRACT:}

The aim of the present study is to compare the accuracy of linear measurements derived from conventional lateral cephalograms (CLC) versus cephalometric images derived from cone beam $C \mathcal{T}(C B \mathcal{L} C)$.

The sample consisted of 10 edentulous dry skulls. Fifteen anatomical landmarks; of which 4 bilateral; were marked on each skull using metallic markers. The distances between these landmarks provided 8 linear measurements commonly used in lateral cephalometric analyses. The skulls were imaged using two techniques, Cateral cephalometric radiograph and cone beam computed tomography. Using the OsiriX ${ }^{\circledR}{ }^{*}$ computer program, 8 linear measurements were measured on the CLC and the CBLC. These measurements were compared with one's made directly on the skull.

The results of this study showed that cephalometric measurement obtained from CBLC images are more representative to the anatomical truth.

1- Visiting Resident, Orthodontic Department, Faculty of Oral and Dental Medicine, Cairo University, Cairo.

2- Assistant Professor, Orthodontic Department, Faculty of Oral and Dental Medicine, Cairo University, Cairo.

3- Professor, Orthodontic Department, Faculty of Oral and Dental Medicine, Cairo University, Cairo.

${ }^{*}$ Available at: http://homepage.mac.com/rosset- antoine/osirix/Index2.html 
Egyptian

Orthodontic Journal

\section{INTRODUCTION}

Currently the cone beam computed tomography (CBCT) is gaining more popularity in orthodontics ${ }^{1-7}$. One of the main concerns is the reliability and accuracy of the measurements taken from lateral cephalometric images derived from $\mathrm{CBCT}$ in comparison to the standard cephalometric and the golden (anatomical truth) measurement.

In the present study we compared direct linear measurements made on human dry skulls (anatomical truth) with that made on conventional lateral cephalograms (CLC) and cephalograms derived from 3D CBCT images (CBLC). The aim is to find out which technique (CLC or CBLC) is more representative to the anatomical truth.

\section{MATERIAL AND METHODS}

The sample consisted of 10 edentulous dry skulls. Hard acrylic was placed between maxilla and mandible to fix them together. Fifteen anatomical landmarks, of which 4 are bilateral, were marked on each skull using metallic markers. The distances between these landmarks provided 8 linear measurements commonly used in lateral cephalometric analysis.

The following linear measurements were taken from each skull:

N-ANS, N-A, Po-Or, ANS-PNS, N-Me, Go-Me, Ar-Go and Go-Pog.

To establish the true distances between the selected anatomic points, skull measurements were independently made by 2 observers 3 times using an electronic digital caliper. The mean of the 6 measurements was taken as the anatomic truth. The left and right measurements for the bilateral linear dimensions (Or-Po, Go-Pog, Go-Me and Go-Co) were averaged.

The skulls were imaged using two techniques, lateral cephalometric radiography and cone beam computed tomography.

1-Digital lateral cephalometric radiograph:

The setup for the conventional digital lateral cephalogram was adjusted with the source to mid-sagittal plane distance maintained at 150 
Egyptian

Orthodontic Journal

$\mathrm{cm}$ and the detector was positioned $15 \mathrm{~cm}$ from the mid sagittal plane for all exposures. Exposure settings were $70 \mathrm{kVp}, 11 \mathrm{~mA}$ and 1 second exposure time*.

The skulls were stabilized in the cephalostat placed on nasion point and 2 ear rods in the external auditory meati and positioned with the Frankfort Horizontal Plane parallel to the floor, the sagittal plane perpendicular to the x-ray beam, and the left side closest to the detector. The central ray was directed at the right external auditory meatus.

Digital images were saved as JPG format and all the above 8 linear measurements were measured using OsiriX ${ }^{\circledR}$ computer program (Fig.1)

2-Cone beam computed tomography:

Images were acquired with the $\mathrm{i}-\mathrm{CAT} \AA$ system*. Operated at 3 to 8 $\mathrm{mA}$ (pulse mode) and $120 \mathrm{kV}$ with a high-frequency generator with fixed anode and $0.5 \mathrm{~mm}$ nominal focal spot size.

The anterior symphyseal region of the mandible of each skull was placed in the chin holder, vertical and horizontal lasers were used to position the skull. Each skull was oriented by adjusting the chin support until the midsagittal plane was perpendicular to the floor, and the horizontal laser reference coincided with the Frankfort horizontal plane.

Lateral scout images were made, and skull position was adjusted so that discrepancies between bilateral structures (e.g., posterior and inferior borders of the mandibular rami and zygomatic arches) were less than $5 \mathrm{~mm}$. A single $360^{\circ}$ rotation, 20 -second scan, comprising 306 basis projections was made of each skull with $17.0 \mathrm{~cm}$ (diameter) x $13.2 \mathrm{~cm}$ (height) field of view. Control of acquisition parameters $(\mathrm{mA}, \mathrm{kVp})$ was automated. Primary reconstruction of the data are automatically performed after acquisition.Secondary reconstruction occurred in real time and provided contiguous color-correlated perpendicular axial, coronal, and sagittal 2D multi-planar reformatting (MPR) slices, with isotropic 0.4-mm. Three-dimensional reconstruction was used to create $2 \mathrm{D}$ simulated lateral skull projection images from the CBCT system (Fig 2).

\footnotetext{
* Plamenca Proline XC, Finland.

* Imaging Sciences International, Hatfield
} 
The linear measurements were made using the same software (OsiriX).

\section{Statistics}

The data was collected, tabulated and analyzed. A reproducibility index, called the Concordance correlation coefficient (CCC), introduced by $\operatorname{Lin}^{8}$ was used. It evaluates the agreement between 2 readings (from the same sample) by measuring the variation for the $45^{\circ}$ line through the origin (the concordance line) ${ }^{8,9,10}$.

\section{Inter-observer error}

The same measurements for all the three groups were measured by two different observer. Paired t test was done to measure the interobserver error.

\section{RESULTS}

Comparison between the mean linear measurements of CLC, CBCL and direct (actual) measurements on the skull are presented in Table (1).

A- Direct measurements on the skull versus CLC

The Concordance Correlation Coefficient revealed poor agreement for N-A, N-Me, Po-Or, Go-Ar, Go-Me and ANS-PNS measurments while $\mathrm{N}-\mathrm{ANS}$ and Go-Pog showed fair and excellent agreement respectively. (Table: 2)

B- Direct measurements on the skull versus lateral cephalogram derived from $\mathrm{CBCL}$

The Concordance Correlation Coefficient revealed excellent agreement for N-ANS, N-A and ANS-PNS, fair agreement for Po-Or and Go-Ar and poor agreement for Go-Me, Go-Pog and N-Me (Table 2).

Inter-observar error:

Paired t-test did not reveal any significant difference between the two observers measurements in all the groups (Table 3,4 \&5). 
Egyptian

Orthodontic Journal

Table (1): Mean of the linear measurements for LC, CBCT and direct skull measurements.

\begin{tabular}{|l|c|c|c|}
\hline \multicolumn{1}{|c|}{ Measurement } & Skull & LC & CBCT \\
\hline N-A & 61.825 & 68.229 & 62.156 \\
\hline N-Me & 109.952 & 119.134 & 110.843 \\
\hline N-ANS & 57.947 & 62.87 & 57.414 \\
\hline Po-Or & 84.614 & 100.372 & 83.86 \\
\hline Ar-Go & 32.071 & 33.466 & 31.997 \\
\hline Go-Me & 93.243 & 92.131 & 81.046 \\
\hline Go-Pog & 89.409 & 89.531 & 80.415 \\
\hline ANS-PNS & 52.463 & 59.404 & 52.246 \\
\hline
\end{tabular}

Table (2): Descriptive statistic for comparison between the CLC, CBLC and direct skull measurements.

\begin{tabular}{|l|c|c|c|}
\hline \multicolumn{1}{|c|}{ Measurements } & Test & LC & CBCT \\
\hline N-A & CCC & $0.026^{* * *}$ & $0.839^{*}$ \\
\hline N-Me & CCC & $-0.006^{* * *}$ & $0.314^{* * *}$ \\
\hline N-ANS & CCC & $0.466^{* *}$ & $0.786^{*}$ \\
\hline Po-Or & CCC & $-0.044^{* * *}$ & $0.730^{* *}$ \\
\hline Ar-Go & CCC & $0.129 * * *$ & $0.636^{* *}$ \\
\hline GO-Me & CCC & $0.251^{* * *}$ & $0.004^{* * *}$ \\
\hline Go-Pog & CCC & $0.834^{*}$ & $0.046^{* * *}$ \\
\hline ANS-PNS & CCC & $0.095^{* * *}$ & $0.836^{*}$ \\
\hline
\end{tabular}

$\mathrm{CCC}=$ Concordance Correlation Coefficient:

$*=\mathrm{p}>0.75=$ Excellent agreement

$* *=0.4>\mathrm{p}<0.75=$ Fair agreement

$* * *=\mathrm{p}<0.4=$ Poor agreement

Volume 37 - June 2010 
Egyptian

Orthodontic Journal

Table 3: Paired t-test measuring difference between 2 observer's measurements in the skull group.

\begin{tabular}{|l|c|c|l|l|}
\hline \multirow{2}{*}{} & \multicolumn{2}{|c|}{ Mean \pm SD } & \multirow{2}{*}{ “t” value } & \multirow{2}{*}{ Prob. } \\
\cline { 2 - 3 } N-A & Observer 1 & Observer 2 & & \\
\hline N-Me & $61.83 \pm 0.33$ & $61.45 \pm 0.41$ & 1.573 & $0.150 \mathrm{NS}$ \\
\hline N-ANS & $109.95 \pm 0.35$ & $110.23 \pm 0.40$ & 1.304 & $0.225 \mathrm{NS}$ \\
\hline Po-Or & $57.95 \pm 1.44$ & $57.85 \pm 1.41$ & 0.588 & $0.570 \mathrm{NS}$ \\
\hline Ar-Go & $32.07 \pm 0.51$ & $84.62 \pm 0.51$ & 0.060 & $0.954 \mathrm{NS}$ \\
\hline Go-Me & $93.24 \pm 0.16$ & $32.25 \pm 0.24$ & 0.266 & $0.826 \mathrm{NS}$ \\
\hline Go-Pog & $89.41 \pm 0.56$ & $89.31 \pm 0.60$ & 0.846 & $0.685 \mathrm{NS}$ \\
\hline ANS-PNS & $52.46 \pm 0.40$ & $52.57 \pm 0.53$ & 0.354 & $0.420 \mathrm{NS}$ \\
\hline
\end{tabular}

Table 4: Paired t-test measuring difference between 2 observer's measurements in the CLC group.

\begin{tabular}{|l|c|c|l|l|}
\hline \multirow{2}{*}{} & \multicolumn{2}{|c|}{ Mean \pm SD } & \multirow{2}{*}{ “t” value } & \multirow{2}{*}{ Prob. } \\
\cline { 2 - 3 } N-A & Observer 1 & Observer 2 & & \\
\hline N-Me & $68.23 \pm 0.57$ & $67.93 \pm 0.67$ & 1.963 & $0.081 \mathrm{NS}$ \\
\hline N-ANS & $119.13 \pm 0.54$ & $118.88 \pm 0.68$ & 1.091 & $0.304 \mathrm{NS}$ \\
\hline Po-Or & $62.87 \pm 1.36$ & $62.89 \pm 1.35$ & 0.176 & $0.864 \mathrm{NS}$ \\
\hline Ar-Go & $33.47 \pm 0.33$ & $33.42 \pm 0.38$ & 0.442 & $0.685 \mathrm{NS}$ \\
\hline Go-Me & $92.13 \pm 0.56$ & $92.03 \pm 0.70$ & 0.487 & $0.638 \mathrm{NS}$ \\
\hline Go-Pog & $89.53 \pm 0.90$ & $89.48 \pm 1.02$ & 0.250 & $0.808 \mathrm{NS}$ \\
\hline ANS-PNS & $59.40 \pm 0.92$ & $59.68 \pm 1.32$ & 0.455 & $0.660 \mathrm{NS}$ \\
\hline
\end{tabular}

Table 4: Paired t-test measuring difference between 2 observer's measurements in the CBLC group.

\begin{tabular}{|l|c|c|c|c|}
\hline \multirow{2}{*}{} & \multicolumn{2}{|c|}{ Mean \pm SD } & \multirow{2}{*}{ “t” value } & \multirow{2}{*}{ Prob. } \\
\cline { 2 - 3 } N-A & Observer 1 & Observer 2 & & \\
\hline N-Me & $62.16 \pm 0.30$ & $62.17 \pm 0.40$ & 0.063 & $0.951 \mathrm{NS}$ \\
\hline N-ANS & $110.84 \pm 0.31$ & $111.28 \pm 0.44$ & 1.820 & $0.102 \mathrm{NS}$ \\
\hline Po-Or & $57.41 \pm 1.16$ & $57.24 \pm 1.14$ & 0.673 & $0.518 \mathrm{NS}$ \\
\hline Ar-Go & $32.00 \pm 0.47$ & $31.61 \pm 0.52$ & 1.402 & $0.195 \mathrm{NS}$ \\
\hline Go-Me & $81.05 \pm 1.22$ & $80.72 \pm 1.27$ & 1.498 & $0.168 \mathrm{NS}$ \\
\hline Go-Pog & $80.42 \pm 1.07$ & $80.37 \pm 1.11$ & 0.509 & $0.623 \mathrm{NS}$ \\
\hline ANS-PNS & $52.25 \pm 0.48$ & $53.71 \pm 1.00$ & 1.409 & $0.192 \mathrm{NS}$ \\
\hline
\end{tabular}




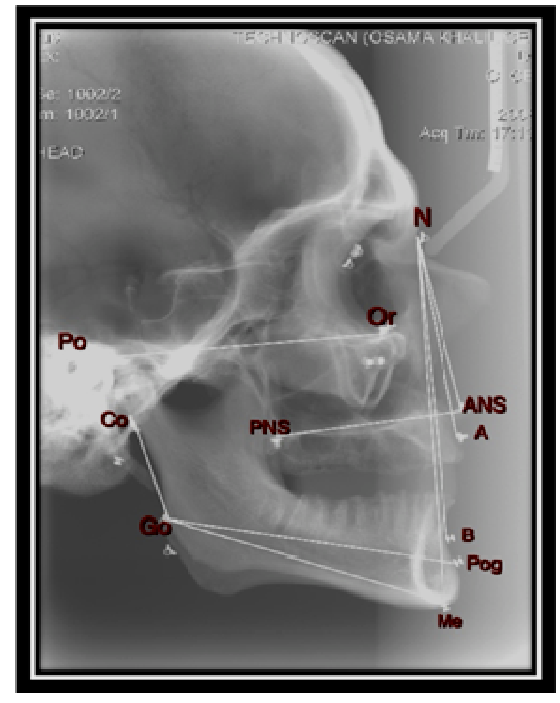

Figure (2): Traced digital lateral cephalogram of the skull

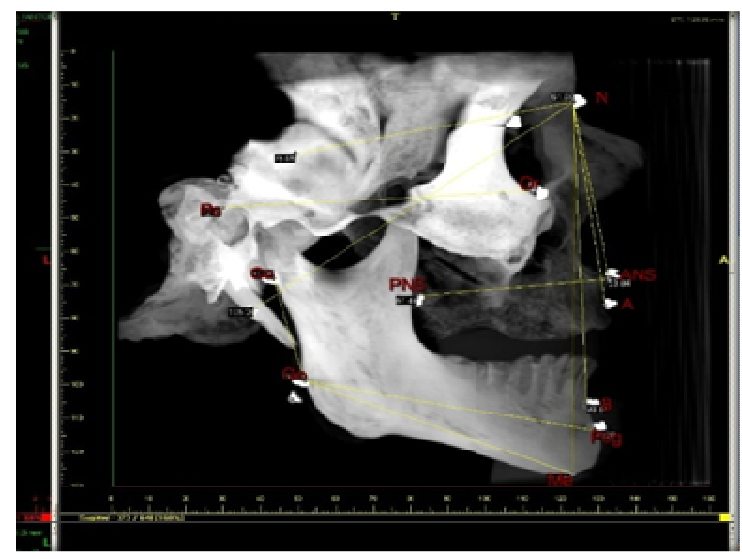

Figure (2): Traced Lateral cephalogram of the skull from three-dimensional cone beam computed tomography scans

\section{DISCUSSION}

Because assessment of anatomic landmarks in 3D is still under development, the transition from the $2 \mathrm{D}$ to the $3 \mathrm{D}$ analysis could be achieved by using CBCT synthesized cephalograms ${ }^{4,7}$. 
In order to evaluate the reliability and accuracy the CLC and CBLC techniques were compaired to the anatomical truth (Direct skull measurements). Previous study applied similar technique but revaluated soft tissue measurements ${ }^{11}$.

The standardization of the skulls position in CBCT machines was done by vertical and horizontal laser beams, C-band around the forehead along with the scout image in which the x-ray beam was parallel to the occlusal plane.

In this study, OsiriX software was utilized for 3D reconstruction of CBCT cuts. Moreover, linear measurements of all lateral cephalometric tracings were calculated using the same software. Such software was proved useful in the display and analysis of large sets of threedimensional medical images.

In order to eliminate identification errors, all cephalometric landmarks (N, A, ANS, B, Pog, Me, Or, PNS, Go, Ar and Po) were previously localized by metallic markers on the skull. Similar approach was described by Kusnoto B et $\mathrm{al}^{12}$ and Adams GL et $\mathrm{al}^{13}$ who have used radiopaque markers on skeletal landmarks as targets for both physical and radiographic measurements. By applying direct physical measurements to these known and marked sites, the actual anatomical distances could be established as a gold standard with which the conventional lateral cephalograms and those obtained from CBCT images could be compared to determine their accuracy.

In the conventional lateral cephalometric image, the skulls were positioned visually in the cephalostat with the Frankfort plane parallel to the floor. On the other hand, skull positioning in the CBCT machine was done using laser level indicators. In addition, digital scout images were acquired to establish minimal bilateral discrepancy before final CBCT acquisition $^{14}$.

Linear measurements obtained from conventional lateral cephalograms and those obtained from CBCT images where compared with those made directly on the skull. The results showed that cephalograms obtained from CBCT images were accurate for most of measurements and the conventional lateral cephalograms had the least 
accuracy. Lateral cephalogram were accurate for ANS-PNS measurement. These results coincide with those of Moshiri $\mathrm{F}$ et $\mathrm{al}^{14}$. The only difference was that their measurements showed good agreement regarding $\mathrm{N}-\mathrm{Me}$, whereas in our study it showed fair agreement. Their conventional lateral cephalograms measurements also showed the least accuracy; but they were accurate for Po-Or and N-ANS.

This difference might be because of errors of projection present in the conventional cephalograms, and therefore the identification of landmarks of bilateral structures (eg, the mandibular line) presents some inaccuracy ${ }^{15}$.

On the other hand, the CBCT data sets can provide undistorted 3D morphology, making it possible to identify craniofacial structures more naturally.

In contrast to conventional cephalograms, the errors due to malposition of the patient during image acquisition could be corrected in CBCT data sets by iterative adjustment. The innate 3D characteristics of the CBCT data set allow for the generation of virtually an infinite number of reformatted images ${ }^{16}$ and orthogonal cephalograms (parallel x-rays). In addition, it is possible to represent the right and left parts of the skull separately, avoiding superimposition of the bilateral structures; the position of the teeth in the 2 sides can be determined, and all non-pertinent structures can be virtually excised ${ }^{17}$.

The results of this study are similar to that of Adams GL et $\mathrm{al}^{13}$ who found that cephalometric evaluation of radiographic images taken in the conventional 2D system often renders both inaccurate and imprecise measurements. In contrast, the relatively new 3D Cephalometric system (Sculptor) provides a much more precise evaluation of linear measures and only slightly inaccurate measures that are underestimated by about $1.0 \mathrm{~mm}$.

\section{CONCLUSION}

- Cephalometric views derived from CBCT are accurate representative to the anatomical truth. 
- Linear cephalometric measurements derived from CBCT do not coincide with the same measurements on the regular cephalometric x-ray.

- Caution should be taken when applying norms derived from regular lateral cephalometric on cephalometric derived from CBCT.

\section{REFERENCES}

1- Baumrind S, Carlson S, Beers A, Curry S, Norri K, Boy RL. Using three-dimensional imaging to assess treatment outcomes in orthodontics: a progress report from the University of the Pacific. Orthod Craniofac Res 2003;6:132-42.

2- Danforth RA, Dus I, Mah J. 3-D volume imaging for dentistry: a new dimension. J Calif Dent Assoc 2003;31:817-23.

3- Danforth RA. Cone beam volume tomography: a new digital imaging option for dentistry. J Calif Dent Assoc 2003;31:814-5.

4- Enciso R, Memon A, Mah J. Three-dimensional visualization of the craniofacial patient: volume segementation, data integration animation. Orthod Craniofac Res 2003;6:66-71.

5- Maki K, Inou N, Takanishi A, Miller AJ. Computer-assisted simulations in orthodontic diagnosis and the application of a new cone beam X-ray computed tomography. Orthod Craniofac Res 2003;1:95-101.

6- Vannier MW. Craniofacial computed tomography scanning: technology, applications and future trends. Orthod Craniofac Res 2003;6:23-30.

7- Hatcher DC, Aboudara CL. Diagnosis goes digital. Am J Orthod Dentofacial Orthop 2004;125:512-5.

8- Lin LI. A concordance correlation coefficient to evaluate reproducibility. Biometrics 1989;45:255-68.

9- Lin LI. Assay validation using the concordance correlationcoefficient. Biometrics 1992;48:599-604.

10- Lin L, Torbeck LD. Coefficient of accuracy and concordance correlation coefficient: new statistics for methods comparison. PDA J Pharm Sci Technol 1998;52:55-9. 
11- Essam Ns, Khaled HA, Saba Al-Hadithiy, Yehya AM. Soft tissue cephalometrics: An overdue evaluation. World J Orthod 2009;10:301-304.

12- Kusnoto B, Evans CA, BeGole EA, Rijk W. Assessment of 3-dimensional computer-generated cephalometric measurements. Am J Orthod Dentofacial Orthop 1999;116:390-399.

13- Adams GL, Gansky SA, Miller AJ, Harrell WE, Hatcher DC. Comparison between traditional 2-dimensional cephalometry and 3- a dimensional approach on human dry skulls. Am J Orthod Dentofacial Orthop 2004;126:397-409.

14- Moshiri M, Scarfe WC, Hilgers ML, Scheetz JP, Silveira AM, Farman AG. Accuracy of linear measurements from imaging plate and lateral cephalometric images derived from cone-beam computed tomography. Am J Orthod Dentofacial Orthop 2007;132:550-560.

15- Bodner L, Sarnat H, Bar-Ziv J, Kaffe I. Computed tomography in the management of impacted teeth in children. J Dent Child 1994;61:370-377.

16- Cavalcanti MG, Vannier MW. Quantitative analysis of spiral computed tomography for craniofacial clinical applications. Dentomaxillofac Radiol. 1998;27:344-350.

17- Cevidanes LHS, Styner MA, Proffit WR. Image analysis and superimposition of 3-dimentional cone beam computed tomography models. Am J Orthod Dentofacial Orthop 2006;129:611-618. 